\title{
A jovem guarda no $A B C$ paulista: música popular, mídia e memória
}

\author{
Herom VARGas \\ Doutor em Comunicação e Semiótica \\ Professor da Universidade Municipal de \\ S. Caetano do Sul (USCS) e da Universidade Metodista de S. Paulo (Umesp) \\ heromvargas@terra.com.br \\ Priscila Ferreira Perazzo \\ Doutora em História Social \\ Professora da Universidade Municipal de S. Caetano do Sul (USCS) \\ prisperazzo@ig.com.br
}

\begin{abstract}
Resumo Por muito tempo, a memória dominante acerca da relação entre cidade de São Paulo e região do Grande ABC (pertencente à região metropolitana paulista) produziu sentidos de que o subúrbio não era o lugar da criação artística ou cultural, em especial a midiática. Contrários a esse ponto de vista, questionamos: quais são as possibilidades efetivas de criação e recriação dos movimentos culturais apresentados pela indústria cultural nessa região? Como é possível dimensionar a movimentação da Jovem Guarda numa área considerada periferia da capital paulista? Partindo disso, pretende-se nesse artigo mapear o movimento da Jovem Guarda no ABC nos anos 1960, com base em entrevistas de história oral com músicos e compositores da localidade, com vistas a demonstrar sua dinâmica e suas características numa região específica.
\end{abstract}

Palavras-chave: música popular; ABC; jovem guarda; rock; história oral.

\section{Introdução}

$\mathrm{O}$ ESTUdOS EM COMUNiCAÇão vêm se interessando, nos últimos anos, pelas relações entre música popular e as mídias, sob vários aspectos. De um ponto de vista histórico, sempre houve um problema a ser enfrentado pelos pesquisadores que é a quase completa inexistência de documentação a respeito do trabalho de músicos e compositores de fora dos grandes centros no Brasil.

A presença das mídias (disco, rádio, televisão etc.) em todo o processo de construção da linguagem da canção e, propriamente, do campo da música popular, proporciona grande possibilidade de documentação dos eventos musicais. No entanto, a própria historiografia, como construção de um passado em função de determinadas necessidades, sejam políticas, ideológicas ou estéticas, releva alguns personagens e fatos em detrimento de outros considerados periféricos.

Esse 'esquecimento' pode ser compensado pelo resgate de histórias marginais pouco citadas ou colocadas como secundárias pela corrente principal. Pesquisas com história oral e memória têm importância significativa, pois utilizam instrumentos que operam fora das estruturas da chamada 'história oficial'. Esses estudos buscam uma 'história múltipla' revelada em narrativas orais das próprias pessoas que as viveram. $\mathrm{O}$ registro e divulgação dessas narrativas podem ser feitos pelas novas tecnologias que atualmente entrelaçam as vidas das pessoas. Por esse proces- 
so, grupos, instituições ou comunidades podem, por si mesmos, produzir, guardar e difundir suas próprias histórias, complementando as diferentes versões, muitas vezes consolidadas na memória oficial.

Atualmente, as ciências creditam importância aos relatos orais pessoais. Narrativas de pessoas que contam suas lembranças transformam-se, para os pesquisadores, em fontes para o entendimento de um objeto ou fenômeno e demonstram que esses discursos são fontes singulares de conhecimento (Worcman; Pereira, 2006). Dessa forma, é possível reconstituir a memória de uma forma mais profunda, diversificada e multilateral, "favorecendo uma compreensão mais diversificada do presente e a mobilização de novos protagonistas na construção de um futuro mais justo" (Alquéres, 2006, p. s/n).

A memória, entendida como aquilo que uma pessoa retém como lembrança (Worcman; Pereira, 2006), pode se expressar oralmente quando ela, numa disposição de 'falar porque alguém quer ouvir', narra suas lembranças. Não se pode operar a vida sem a memória individual (aquilo que nos aconteceu, quem somos, como foi nossa vida, quem são amigos e parentes, como nos relacionamos com os outros, o que achamos do mundo etc.), porque "ela é a parte mais central da consciência humana ativa, e é essencialmente oral" (Thompson, 2006, p. 18).

Os recursos promovidos pela história oral realçaram a importância da memória individual nas sociedades contemporâneas e possibilitaram a recuperação do sujeito comum como protagonista da (sua) história. A posição que se assume aqui é a de que a história oral é um campo interdisciplinar que conta com uma abordagem ampla, sendo "interpretação da história, das sociedades e culturas em processo de transformação, por intermédio da escuta às pessoas e do registro das histórias de suas vidas" (Thompson, 2006, p. 20). Com o advento das novas tecnologias, que marcam as relações no século XXI, as memórias pessoais e individuais podem ser registradas e divulgadas por meios modernos de comunicação audiovisuais e eletrônicos (Thompson, 2006) ${ }^{1}$.

Esta investigação, que interliga música popular, mídia, história oral e memória, procura observar a produção da cultura, em especial a midiática, da mesma forma que procura entender "como as pessoas utilizam a cultura" (Thompson, 2006, p. 27). Nesse campo, as narrativas orais e pessoais podem inovar o olhar científico parar contribuir para a difícil identificação dos usos das linguagens e da cultura.

A opção da 'história oficial' da música popular brasileira sempre foi priorizar a produção carioca e, secundariamente, a paulista e as de outros estados em detrimento das histórias musicais locais. Certamente, por conta da centralização das indústrias culturais do campo popular musical ter ocorrido no Rio de Janeiro (a primeira gravadora - Casa Edison -, as primeiras emissoras de rádio etc.), boa parte dos trabalhos sobre música popular é produzida em função dessa centralidade geográfica. Por conta disso, outras regiões têm suas histórias contadas em retalhos quando suas músicas aparecem no cenário midiático nacional ou são tratadas, muitas vezes, como repetição de modelos provenientes dos centros, meras adaptações, quando não simplesmente anuladas.

Assim, a questão que se coloca é como aparecem as marcas da indústria midiática numa região específica, ou como essas marcas são trabalhadas pelo coletivo local em função tanto das forças da comunicação massiva quanto de suas particularidades? Nas palavras de Martín-Barbero, parafraseando Walter Benjamin:

a razão secreta do êxito e a do modo de operar da indústria cultural remetem fundamentalmente ao modo como esta se inscreve na e transforma a experiência popular. E a essa experiência - que é memória e práti$\mathrm{ca}$ - remete também o mecanismo com o qual as classes populares fazem frente inconsciente e eficazmente ao massivo [...] (Martín-Barbero, 2001, p. 120-121).

A importância de analisar a produção musical e midiática de regiões específicas está na possibilidade de desvendar um cenário que se esconde sob o manto das histórias centrais ou sob a visão generalizante dos meios de comunicação como instrumentos de massificação. Sobre o caso do Grande ABC paulista a memória dominante acerca da relação entre a capital e essa região produziu por muito tempo um entendimento de que o subúrbio, como é identificado, era o lugar da reprodução e da repetição, e não o da produção ou criação (Martins, 2002). Sobretudo, ao se falar do ABC, surge no imaginário da sociedade um espaço de trabalho fabril, de bairros operários e movimentação sindical. Dessa forma, como seria possível promover arte e cultura onde apenas existia o trabalho nas indústrias? Quais as possibilidades de criação e recriação dos movimentos culturais apresentados pela indústria cultural nesse local?

Para nós, a questão que se coloca é: como é possível conhecer e dimensionar a movimentação da Jovem Guarda no Grande ABC nos anos 1960, área considerada periferia da capital paulista, porém com índices de riqueza e crescimento e certas características peculiares de identidade?

Pretende-se nesse artigo mapear a relação do movimento da Jovem Guarda com os artistas da região,

1 Atualmente, os depoimentos de história oral podem ser registrados em vídeo, o que modifica a produção da fonte oral, que passa a ser imagem em movimento. Para esta pesquisa, as entrevistas foram registradas em áudio, prática ainda comum. No entanto, o Núcleo de Pesquisadores de Memórias do ABC/Universidade Municipal de S. Caetano do Sul, ao qual os autores se integram, produz entrevistas de história oral em vídeo, que, em breve, estarão à disposição no HiperMemo - Acervo Hipermídia de Memórias do ABC. 
com base em entrevistas de história oral com músicos e compositores da localidade.

As entrevistas de história oral realizadas para esse estudo podem se caracterizar como 'entrevistas temáticas', de acordo com as definições de Verena Alberti (2005), que versam sobre a participação do entrevistado no tema escolhido e que são adequadas para "o caso de temas que têm estatuto relativamente definido na trajetória de vida dos depoentes. (...) Nesse caso o tema pode ser de alguma forma 'extraído' da trajetória de vida mais ampla e tornar-se centro e objeto das entrevistas" (Alberti, 2005, p. 38). Também pode-se chamar essas entrevistas de 'relatos de vida', que se apresentam como "a possibilidade de reunir dois aspectos da mesma realidade social que normalmente aparecem dissociados: o socioestrutural e o sociossimbólico". Os relatos de vida, que se expressam por histórias pessoais, são pretextos para "descrever um universo social desconhecido, antes negado pela prática sociológica" (Grisa, 2003, p. 289).

\section{A Jovem Guarda e os anos 1960}

A Jovem Guarda tem a ver com um momento bastante significativo na história da música popular brasileira, sobretudo com relação ao estágio midiático a que corresponde. Os anos 1960 compreendem uma série de processos de transformações sociais, econômicas e estéticas e que, em boa medida, se relacionam com mudanças no campo midiático. A Jovem Guarda pode ser entendida como um dos primeiros fenômenos da cultura pop no Brasil (Martins, 1966; Medeiros, 1984; Feliciano, 1995) fundamentada no crescimento da publicidade e da televisão. Esses fenômenos estavam ancorados nos processos de urbanização e industrialização vistos, com maior destaque, no eixo Rio-São Paulo a partir dos anos 1950, e na crescente disseminação da cultura norte-americana na América Latina desde os anos de 1930, mas intensificada após a Segunda Guerra Mundial (Tota, 2000).

A música popular aproveitou-se dessas transformações nas mídias e na cultura e criou interfaces com novos meios. O rádio já era, nos anos 1930 e 1940, no Rio de Janeiro e em São Paulo, um canal importante de divulgação musical. Mais que isso, mantinha com a canção um histórico de determinações mútuas, desde participar da consolidação do formato das composições até ajudar a definir modos de consumo musical e de audição (Valente, 2003). Como instrumento de divulgação, tornou-se centro da canção popular, pois não havia caminhos que levassem o compositor e sua criação ao grande público sem passar pelos programas de rádio, em especial os de calouros que, a cada edição, colocavam no mercado levas de intérpretes cuja longevidade na carreira só seria definida pelas suas qualidades vocais e pelos espaços que conseguisse cavar no veículo.

E a TV, por sua vez, relacionou-se com a canção, inicialmente como espaço de divulgação. Porém, ao longo do processo de consolidação do veículo (entre 1950 e 1960), outras formas de inter-relação foram criadas, sobretudo com o apelo de elementos das linguagens visuais: roupas, dança, cabelos, adereços corporais, design de instrumentos, luzes e cores.

Nesse momento, desenvolve-se nos EUA um novo gênero musical fundado no rhythm and blues e na folk music - o rock - cuja linguagem sintonizou-se à da TV, em boa medida, por conta das performances de músicos e cantores.

No Brasil, esse gênero começou a ser ouvido ao final dos anos 1950, tanto por cantores norte-americanos como pelas primeiras gravações feitas por brasileiros. A primeira foi Nora Ney, cantora de samba-canção e bolero, com a gravação de Rock Around the Clock, em 1955. Outro foi Cauby Peixoto, com Rock'n'Roll em Copacabana, composição de Miguel Gustavo, lançada em 1957. Carlos Gonzaga, um cantor com experiência, lançou as versões de Diana, Oh! Carol e o tema Bat Masterson, famoso seriado de TV. Outros pioneiros foram os irmãos Tony e Celly Campello, com sucessos e apresentações no primeiro programa de TV para a juventude: o Crush em Hi-Fi, da TV Record, em 1959 (Pugialli, 1999). Além desses, houve também Demétrius, Ronnie Cord, Ed Wilson, Eduardo Araújo etc.

Uma segunda geração do rock nacional, batizada de Jovem Guarda, se desenvolveu em torno do programa de televisão com mesmo nome: Jovem Guarda (TV Record - 1965-1968) e de outros programas concorrentes em outras emissoras (como o Programa Julio Rosemberg, na TV Tupi; o Mini Guarda, de Ed Carlos, na TV Bandeirantes; O Bom, de Eduardo Araújo, na TV Excelsior; e o Juventude em Brasa, na TV Paulista).

Entretanto, o início da Jovem Guarda não está apenas ligado à TV. Alguns programas de rádio e seus respectivos apresentadores ou DJs também souberam aproveitar o apelo do rock na juventude. São eles: Hoje é Dia de Rock (com Jair Taumaturgo, na Rádio Mayrink Veiga carioca), Os Brotos Comandam (com Carlos Imperial, na Rádio Guanabara, no Rio de Janeiro), Ritmos para a Juventude (com Moreira Jr. e Líria Marçal, na Rádio Nacional de S. Paulo) e Festival de Brotos (com Enzo de Almeida Passos, na Rádio Bandeirantes) (Feliciano, 1995; Pugialli, 1999; Fróes, 2000).

Também no cinema, a estética do rock apareceu com sucesso, desde os filmes de James Dean e Elvis Presley nos anos 1950, até os filmes de Roberto Carlos, como Roberto Carlos em Ritmo de Aventura. Na imprensa, toda a movimentação musical e comportamental foi registrada em novas revistas juvenis e em outras pautadas nas novidades, como Revista do Rádio e Revista do Rock, no Rio de Janeiro, e Intervalo, em São Paulo.

Em termos musicais, as primeiras referências do 
rock foram os cantores/músicos Elvis Presley, Chuck Berry, Little Richard e Jerry Lee Lewis. Porém, dois grupos se destacaram nos final dos anos 1950 e suas influências chegaram ao Brasil: o norte-americano The Ventures e o britânico The Shadows. Esses conjuntos tocavam twist ou o que chamaríamos hoje de surf music, um rock instrumental, com andamento mediano voltado para dança, com a melodia feita pela guitarra solo sem nenhum tipo de efeito sonoro. Ambos eram formados por duas guitarras (solo e base), baixo, bateria simples e, eventualmente, um naipe de sopros. Quando havia letras cantadas, tratavam invariavelmente, de romances, rebeldia juvenil, o cotidiano etc. Era comum os músicos se apresentarem com terno e gravata das mesmas cores.

O The Shadows marcou a presença de grupos ingleses nas paradas de sucesso, fenômeno que seria denominado como british beat com o aparecimento de The Beatles, Rolling Stones, Herman's Hermits, Animals e outros.

No Brasil, a influência desses grupos foi fundamental na formação de jovens que se deslumbravam com a possibilidade de tocar rock e com as novas performances. Traduções dessa música e dessa formação instrumental estavam nos conjuntos Jet Blacks, The Jordans, The Clevers (depois Os Incríveis) e Renato e seus Blue Caps ${ }^{2}$. Era comum eles se apresentarem para acompanhar os jovens cantores, como foram os exemplos de Roberto Carlos e Jet Blacks, Tony Campello e The Jordans.

\section{O ABC e a Jovem Guarda}

A região do $\mathrm{ABC}$ paulista, por uma série de condições históricas, foi cenário importante do crescimento nacional, especificamente paulista, após a Segunda Guerra Mundial. Pela sua posição entre o Porto de Santos e São Paulo e pela presença da linha férrea, seu espaço foi escolhido como sede de várias indústrias que se instalavam no país no período, sobretudo as automobilísticas. O local já exercera esse papel intermediário no período cafeeiro com a construção da Estrada de Ferro Santos-Jundiaí, no entanto, essa era a vez da abertura de uma rodovia (caso da Via Anchieta, inaugurada em 1947) servir de elo no transporte de mercadorias e pessoas.

A novidade da TV em São Paulo ocorreu no período em que, na região, eram criadas as primeiras emissoras de rádio locais. Enquanto, em 1950, Chateaubriand inaugurava a TV Tupi e, em 1953, entrava no ar a TV
Record, de Paulo Machado de Carvalho, na mesma década surgiram quatro emissoras de rádio na região:

Rádio Clube de Santo André, criada em 1953;

Rádio Emissora ABC (atual Rádio ABC), também em Santo André e criada no mesmo ano;

Rádio Independência, situada em São Bernardo do Campo e inaugurada em 1957;

Rádio Cacique, colocada no ar em 1958 e com sede em São Caetano do Sul (Santarnecchi, 2004; Médici, 2000).

As emissoras de rádio não tinham um raio de transmissão muito grande, o que limitava o público ouvinte aos que moravam na região e adjacências. Por conta da proximidade com a capital, sofriam com a concorrência das emissoras de São Paulo, mais potentes, mais antigas e com uma estrutura constituída: anunciantes, profissionais mais qualificados e cast.

Assim, conforme depoimentos obtidos ${ }^{3}$, era comum que fossem para a capital os artistas que se sobressaíam nas rádios locais e que caíam no gosto popular da região. São, por exemplo, os casos do cantor Haroldo José e do Duo Guarujá, artistas de sucesso no ABC e também em São Paulo ${ }^{4}$. Por outro lado, essa concorrência fez com que as emissoras locais, em busca de audiência, dessem espaços aos cantores de sucesso que vinham da capital, conhecidos também pela televisão, e colocassem os artistas da região na abertura das apresentações principais ou, no caso dos músicos, acompanhando a famosa atração.

Por isso, essas rádios, apesar da importância regional que tiveram, eram tratadas pelos ouvintes, muitas vezes, de forma secundária, sem a mesma deferência com que eram tratadas as rádios de São Paulo e todos os artistas que vinham de lá para se apresentarem no ABC.

Também por causa da proximidade geográfica e pela ação de veículos como a televisão, vários aspectos culturais da vida cotidiana tinham origem na capital. Um dos casos mais nítidos é o da música popular. O que se ouvia no centro urbano mais próximo, também o era na região; o que era consumido, as modas, os comportamentos, também chegavam de São Paulo. Esse trânsito, no entanto, não se dava apenas em mão única, nem o que chegava ao ABC era tratado da mesma maneira como era tratado na origem. Em outras palavras, várias manifestações na região, mesmo que parecidas com as de São Paulo e do Rio de Janeiro ou provenientes delas, tinham um perfil diferente no âmbito local, movimentavam outros sentidos e davam significados a estruturas que não existiam no mesmo formato na capital. Por exemplo, se a presença marcante do imigrante italiano no ABC e o início da migração nordestina nos pós-guerra aproximava o perfil da região ao de alguns bairros de São Paulo, o caráter 
ainda um pouco rural da região implicava algumas adaptações não vistas na capital.

Para usar a terminologia de Martín-Barbero (2001, p. 17), são as matrizes culturais locais - cultura e sociabilidade - que ativam determinadas competências de recepção e alteram os sentidos dos processos massivos de comunicação. Não é possível tratar as manifestações de uma indústria cultural (como é a da canção popular e todo o seu campo) de forma universalizada. Se há uma força de massificação que age com base em um centro hegemônico para as periferias fazendo-as reproduzirem padrões, há também movimentos contrários ou em outras direções que traduzem as informações massificadas ou as redirecionam para gerarem outros sentidos em outros usos sociais. Ou seja, a canção de sucesso em São Paulo ou Rio de Janeiro pode ser tocada e ouvida em outros locais de formas diferenciadas, com respostas distintas das mais conhecidas.

Um exemplo curioso eram os clubes onde vários grupos da região tocavam. O fenômeno dos bailes em clubes era muito freqüente. As orquestras eram formações instrumentais conhecidas e tocavam gêneros de sucesso nos anos 1950 (sambas, valsas e boleros). O rock alterou esse tipo de evento. Além do estilo musical, mudou a formação instrumental dos grupos (com os instrumentos elétricos), alterou as relações entre homem e mulher, especialmente na dança, e iniciou a redefinição da festa jovem contrapondo-se ao baile para todas as idades.

Isso certamente foi adaptado no $\mathrm{ABC}$ e, pouco a pouco, os bailes possibilitaram novos circuitos nas cidades onde era possível ouvir e dançar o rock. Clubes se adaptaram, salões foram criados, grupos se formaram, roupas e hábitos novos foram cultivados, sempre em favor de alguns modelos vinculados à juventude e à rebeldia que, por sua vez, apareciam nas letras das canções e nas imagens dos cantores na televisão.

Se esse processo ocorreu em vários lugares onde o rock prosperou, é possível afirmar que, em cada um desses espaços, houve respostas peculiares e singulares que construíram configurações locais para um fenômeno que parece ser maior que isso.

O rádio, por exemplo, com seus programas de calouros, espaços de entrada para a carreira de sucesso nos anos 1950, tornou-se secundário para os jovens roqueiros, uma vez que não havia programas suficientes para aparecerem ao público. A saída eram festas em casas de família ou clubes novos e antigos que organizavam bailes movidos pela nova música da juventude.

Em Santo André, são os casos do Ocara Clube, Aramaçan e Primeiro de Maio. Em São Caetano do Sul, havia o Esporte Clube S. Caetano e o Buso Palace. Em São Bernardo do Campo, os locais principais eram a Associação dos Funcionários Públicos e o Odeon. Este último era um caso curioso. Havia em
São Bernardo uma filial da empresa de discos Odeon entre 1950 e 1960. Basicamente, funcionava como distribuidora de discos para a região (certamente, sinal de importância do ABC no mapa do consumo fonográfico). Ali, havia um espaço reservado para festas onde tocaram vários grupos de rock.

Alguns outros espaços foram adaptados para shows promovidos pelas emissoras de rádio, casos de cinemas, estádios e praças reservados para espetáculos especiais com cantores famosos e acompanhamento feito pelos conjuntos da região.

E quais eram os grupos musicais da região do Grande ABC na década de 1960?

Entre os muitos que apareceram, um dos primeiros foi Os Elétrons. José Rolim foi o guitarrista do grupo e esteve entre seus criadores:

Vim para cá em 1962. Fui estudar no Colégio Américo Brasiliense, em Santo André, e lá conheci o pessoal dos Elétrons. Você está num colégio e gosta de música, seu assunto é música, então você logo se relaciona. Conheci o Sidnei Barbosa lá, o Ageu Marquês, o José Aparecido, o Serginho Demary e logo depois veio o Marco Antonio.

Uma das primeiras apresentações que fizemos foi na chácara do Clube Primeiro de Maio. O Serginho, já falecido, queria tocar com a gente. Ele tocava bongô, mas tinha um grande trunfo: ele tinha um carro e a gente não tinha. Um dia ele falou: 'Vamos tocar em algum lugar?' Pusemos o equipamento dentro do carro dele, uma Vemaguet, e fomos para o Primeiro de Maio. Ele montou o equipamento na chácara, tinha uns terraços e tocamos a primeira vez. Fomos a primeira banda que tocou numa domingueira da chácara (Depoimento Rolim).

Dois componentes d'Os Elétrons entraram, algum tempo depois, n'Os Dinâmicos, conjunto que já existia em Santo André. O repertório era formado por músicas do The Shadows e do The Ventures, prática definida hoje como cover. Conforme pode-se perceber nas fotos que o depoente Rolim tem no seu fotolog na internet ${ }^{5}$, a formação instrumental, poses, roupas e cortes de cabelo comprovam a semelhança estética da performance.

O mesmo é possível perceber quando se ouve as composições próprias do grupo e gravadas nos limites tecnológicos dos anos 1960. Rolim guardou duas delas e, ao ouvi-las hoje, é impossível não perceber, nos aspectos musicais, a marca daqueles conjuntos. Uma se chama Hop Hop e a outra, Puf, palavras lúdicas e, de certa forma, onomatopéicas em relação à sonoridade do arranjo. Nelas, ambas instrumentais, há um tema melódico feito pela guitarra e acompanhado por guitarra, baixo e bateria dentro dos padrões de The Ventures e The Shadows. 
Isso demonstra que as estéticas musicais e de performance influenciaram bastante os jovens que iniciavam, de maneira autodidata, suas experiências musicais. Praticamente todos os músicos do ABC entrevistados falam dessa influência. Essa relação de idolatria está na reprodução da estética musical, no cover e nas composições próprias, nos trejeitos das performances ao vivo, nas roupas etc.

Outro grupo de rock importante na região nos anos 1960 foi Os Botões. O nome inicial era The Snakes, criado por volta de 1965 e também tocando músicas de The Shadows e The Ventures. O nome Os Botões veio em 1968 - segundo Fróes (2000), mudado por conta do grupo homônimo de Erasmo Carlos -, tornando-se solicitado para bailes nos clubes locais com músicas cantadas, sucessos do The Beatles. O cantor era José Carlos Gonzalez, conhecido como Carlão.

Com o desenvolvimento do grupo, em 1969, surgiu a possibilidade de gravar um disco compacto pela RCA com duas músicas. Entretanto, para isso, alguém da gravadora sugeriu a mudança de nome do grupo para um nome em inglês. Foi daí que surgiu The Buttons e seu cantor denominou-se Dave MacLean:

Tinha um amigo nosso, o Dorival Marcos, que era amigo do Nelson Robles, locutor da Rádio Cacique, de São Caetano. Ele gravava na RCA Victor e levou a gente para gravar lá. Ele era sócio do Buso Palace [clube em São Caetano]. Ele levou a gente num dos intervalos da gravação dele para a gente fazer um teste. Nós pusemos os três microfones na frente, a bateria e gravamos o teste. A música chamava Whispering e do outro lado 25 Milles. Esse 25 Milles era uma música de negão. Depois, quando fomos para um estúdio de verdade, nós não conseguimos gravar melhor, então foi lançada a gravação ao vivo, sem dizer que era ao vivo. Esse disco saiu com essas duas músicas em 1969. Era um compacto e foi sucesso no Brasil todo (Depoimento MacLean).

The Buttons durou mais algum tempo. Seus integrantes gravaram um LP (The Buttons, RCA, 1970), se apresentaram no Programa Julio Rosemberg (TV Tupi) e no Juventude em Brasa (TV Paulista), até o grupo se desmanchar por falta de organização interna, apesar do sucesso inicial. Quem continuou cantando foi Carlão, com o nome inglês Dave MacLean. Fez sucesso internacional com as canções Me and You (tema da telenovela Os Ossos do Barão, da TV Globo, de 1973), Tears e We Said Goodbye.

A experiência d'Os Botões está ligada a outra de caráter empresarial no campo musical. Um dos componentes do grupo, Alaor, com um sócio, abriu uma fábrica de guitarras e baixos em São Caetano do Sul, a Snake. Por um tempo, seus instrumentos rivalizaram com os da Del Vecchio e os da principal fabricante nacional, a Tranquillo Giannini (fundada em 1990) ${ }^{6}$. Depois de alguns anos, a empresa se mudou para a Vila Califórnia, bairro de São Paulo que faz divisa com São Caetano do Sul. Nos anos 1970, a Snake criou outra marca, a Ookpik, e diversificou os trabalhos com a produção de amplificadores e alto-falantes para instrumentos musicais.

Outro grupo que surgiu em São Caetano do Sul na época d’Os Botões foi o Porão 99. Este, porém, sempre se manteve com atuações em bailes. Chegou a gravar um LP nos anos 1970, mas não gerou nenhuma repercussão. Empresariado por Álvaro José e com famosas performances de palco, Porão $99 \mathrm{fez}$ sucesso em bailes no ABC e em São Paulo. Seu repertório era conhecido por covers de Led Zeppelin e Deep Purple, importantes grupos de rock dos anos 1970.

Um conjunto que, de certa forma, foi mesmo misterioso era o Enigma. No dicionário do rock brasileiro escrito por Marcelo Dolabela (1987, p.67), ele aparece como de Salvador (BA). No entanto, nas entrevistas feitas para esta pesquisa, os depoentes apontam que o grupo se formou em Ribeirão Pires (município do Grande ABC) composto por dois baianos que estavam pela região, o guitarrista Pepeu Gomes e o baterista Odair Cabeça de Poeta, mais o baixista paulista Pedrão.

Pepeu esteve em São Paulo e no ABC entre 1968 e 1969 e chegou a participar do programa O Bom, de Eduardo Araújo (TV Excelsior) ${ }^{7}$. Posteriormente, no início dos anos 1970, formou Os Novos Baianos, importante grupo do pós-tropicalismo. Odair fundou com Geraldo Rosa (este do ABC) o grupo Capote. Pedrão, por sua vez, integrou o Som Nosso de Cada Dia, grupo de rock progressivo do início dos anos 1970, com o tecladista e saxofonista Manito (ex-Os Incríveis).

Ao relacionar a cena rock do $\mathrm{ABC}$ ao rádio nos anos 1960, aparecem os casos de dois grupos cuja história está ligada a um programa que existiu na Rádio ABC: o Brotomania. O primeiro grupo era Os Comanches (que depois mudou o nome para Os Cheyennes) e o segundo era o Teen Players. Destes, o que mais se apresentou na emissora foi o segundo. O Brotomania foi um programa de auditório ao vivo que ia ao ar aos sábados, das $14 \mathrm{~h}$ às 17h. Quem apresentava era Roberto Spíndola, também diretor da rádio. Participavam cantores e grupos da região e convidados de fora que eram acompanhados pelos conjuntos Teen Players e Os Comanches. Em seu depoimento, Wilson Maziero (conhecido como Zorbha) conta como era tocar no programa:

Não era um programa de calouros. Era um programa com artistas da região. Às vezes vinham alguns convidados. Não tinha disputa.

Eu lembro de um cantor que já fazia muita televisão em 
São Paulo, que nós acompanhamos: Maurice. Cantava músicas em francês. Também veio um rapaz que ficou com a gente muito tempo. Era o Ed Carlos.

Os cantores iam a esse programa cantar e a gente fazia o acompanhamento. A gente ensaiava durante a semana, marcava as músicas que iam ser apresentadas e aí no sábado, tocava. Tudo ao vivo, na raça. Apesar de que tinha o ensaio durante a semana.

Tinha o fã-clube de cada um. Como era no auditório, então o cantor convidava os amigos para ir prestigiar (Depoimento Maziero).

Além desse programa da Rádio ABC, a Rádio Cacique tinha o programa Discoteca para Brotos, com a locução de Nelson Robles. Entretanto, não era ao vivo, apenas tocava discos com os sucessos de iê-iê-iê que os ouvintes pediam.

Dos cantores que estavam no $\mathrm{ABC}$ e fizeram sucesso fora da região, dois são destaque. Um é Ed Carlos que, além de ter participado do Brotomania, foi para São Paulo, conheceu Roberto Carlos e teve um programa na TV Bandeirantes. Outro foi Jerry Adriani, nascido em São Paulo e com a infância passada em São Caetano. Depois de ter cantado em programas na Rádio Cacique (São Caetano do Sul) e no Programa Julio Rosemberg, entre outros, conseguiu um contrato para gravação no Rio de Janeiro, fez muito sucesso e é conhecido até hoje.

Carlos Gonzaga foi outro cantor ligado ao ABC, apesar de não ter nascido e nem ter iniciado carreira na região. Pioneiro no rock brasileiro, ao lado de Ronnie Cord, Tony e Celly Campello e Demetrius, Gonzaga cantava boleros, valsas e guarânias até interpretar versões feitas por Fred Jorge a partir de 1958.

\section{Conclusão}

$\mathrm{Na}$ trilha do percurso dos grupos de rock do ABC, nos anos 1960, percebe-se como a Jovem Guarda foi importante para a carreira de jovens músicos que construíam, naquele momento, uma cena roqueira, numa região de características histórico-culturais peculiares.
É certo que o ABC foi um local que acompanhou, no que diz respeito à musica popular, o que ocorria em São Paulo, fosse com cópias ou soluções locais.

Os depoimentos desses cantores demonstram como certos elementos do campo da música popular se construíram e se relacionaram tanto com a cena local quanto com os eventos que ocorriam em São Paulo: as emissoras de rádio e seus programas, os clubes e outros espaços para bailes, a presença da juventude local nessas festas, os conjuntos do ABC e, até mesmo, a presença de uma importante fábrica de instrumentos. No ABC dos anos 1960, espaços urbanos foram recriados ao sabor das novas propostas de sociabilidade da cultura jovem. As instâncias de consagração na estrutura do campo musical no âmbito regional também foram transformadas, tanto em conflito com as estruturas antigas (por exemplo, os programas de calouros nas rádios ou os gêneros musicais considerados 'velhos' como o samba-canção), como com os espaços na capital paulista. Novamente, eram os casos das rádios e os clubes que disputavam um público dividido entre o lazer local e o que vinha de São Paulo pela televisão com mais glamour.

Da mesma forma é possível perceber nos relatos orais dos entrevistados, como certos elementos da linguagem da canção popular (sobretudo a música e as performances) foram recebidos e incorporados pelos músicos locais. Esses conjuntos, de maneiras variadas ou seguindo alguns padrões conhecidos, funcionavam como mediadores das novidades que surgiam na área musical e traduziam os novos estilos musicais e performáticos para um público que só conhecia as novas estéticas por meio da televisão e do cinema.

A cena completa se vê nos programas das TVs de São Paulo, com o apelo do sucesso, sobretudo pelos programas mais citados: Jovem Guarda e Julio Rosemberg. Muitos artistas se dirigiram a esses programas na busca pelo reconhecimento, pelo contrato com uma gravadora paulistana ou pelo glamour visualizado nas mídias (TV, revistas ilustradas, cinema). Afinal, eram esses os elementos que preenchiam o imaginário de sucesso dessa juventude numa região considerada periférica em relação ao 'desenvolvimento cultural' da capital paulista e que hoje se manifestam tanto mais na memória individual que propriamente na oficial.

\section{Referências}

ALBERTI, Verena. Manual de história oral. 3. ed. Rio de Janeiro: Ed. FGV, 2005.

ALQUÉRES, Hubert. Apresentações. In: WORCMAN, Karen; PEREIRA, Jesus (Coord.). História falada: memória, rede e mudança social. São Paulo: Sesc/Museu da Pessoa/Imprensa Oficial, 2006. p. s/n.

DOLABELA, Marcelo. ABZ do rock brasileiro. São Paulo:
Estrela do Sul, 1987.

FELICIANO, Fátima A. Jovem Guarda: 30 anos do primeiro fenômeno pop musical de massas do Brasil - música e TV. Comunicação \& Sociedade. (Umesp) n. 24, p. 51-76, 1995.

FRÓES, Marcelo. Jovem Guarda em ritmo de aventura. São Paulo: Ed. 34, 2000. 
GRISA, Jairo. Histórias de ouvintes: a audiência popular no rádio. Itajaí: Univali, 2003.

MARTÍN-BARBERO, Jesús. Dos meios às mediações: comunicação, cultura e hegemonia. 2. ed. Rio de Janeiro: Ed. UFRJ, 2001.

MARTINS, José de Souza. Subúrbio. 2. ed. São Paulo: Hucitec/Unesp, 2002.

MARTINS, Rui. A rebelião romântica da Jovem Guarda. São Paulo: Fulgor, 1966.

MEDEIROS, Paulo de Tarso Cabral. A aventura da Jovem Guarda. São Paulo: Brasiliense, 1984.

MÉDICI, Ademir. Programa de auditório. Santo André: Fundo de Cultura de Santo André/Prefeitura Municipal, 2000. PUGIALLI, Ricardo. No embalo da Jovem Guarda. Rio de Janeiro: Ampersand, 1999.

SANTARNECCHI, Domingo Glenir. A atuação do rádio no Grande ABC. Comunicação apresentada no II Encontro Nacional da Rede Alfredo de Carvalho. GT História da Mídia Sonora. Florianópolis, abril de 2004.

THOMPSON, Paul. Histórias de vida como patrimônio da humanidade. In: WORCMAN, Karen; PEREIRA, Jesus (Coord.). História falada: memória, rede e mudança social. São Paulo: Sesc/Museu da Pessoa/Imprensa Oficial, 2006. p. 17-44.

TOTA, Antonio Pedro. O imperialismo sedutor: a americanização do Brasil na época da segunda guerra. São Paulo: Cia. das Letras, 2000.

VALENTE, Heloísa de Araújo Duarte. As vozes da canção na mídia. São Paulo: Via Lettera/Fapesp, 2003.

VARGAS, H.; PERAZZO, P.F.; DONATO, R. O desenvolvimento musical do ABC na década de 1950. Raízes. n. 33, p. 66-71, 2006.

VARGAS, H.; PERAZZO, P.F.; PEREIRA, S.L. Música popular nas rádios do ABC: memória musical e cultura regional nos anos 1950 e 1960. Galáxia. (PUC-SP) n. 12, p. 27-41, 2006.

WORCMAN, Karen; PEREIRA, Jesus (Coord.). História falada: memória, rede e mudança social. São Paulo: Sesc/ Museu da Pessoa/Imprensa Oficial, 2006.

\section{Depoimentos gravados}

FLORENTINO, João Alberto M. - Santo André, 06/09/2007.

JOARES, Marco Antonio (Kaximbo) - São Caetano do Sul, 03/08/2007.

MACLEAN, Dave - São Bernardo do Campo, 23/08/2007.

MAZIERO, Wilson R. (Zorbha) - Santo André, 19/10/2007.

ROLIM, José - São Caetano do Sul, 03/08/2007.

SUKORSKI, Carlito - Santo André, 26/09/2007.

VICENTIM, Sérgio (Papagaio) - Santo André, 24/08/2007.

ZAGO, Paulo Roberto - Santo André, 12/09/2007.

\title{
The Jovem Guarda Music Movement in the ABC Paulista Region: Popular Music, Media and Memory
}

\begin{abstract}
For a long time, the dominant memory about the relationship between the city of São Paulo and the Greater ABC (which belongs to the São Paulo metropolitan region) was that the suburb was not the place of artistic or cultural creation, especially the mass-media-based type. Disagreeing from this point of view, we ask the questions: what are the effective possibilities of creation and recreation of the cultural movements presented by the cultural industry in this region? How can we measure the Jovem Guarda movement in an area that is considered Sao Paulo's periphery? From this perspective, the article aims to map the Jovem Guarda movement of the ABC region in the 1960s, using oral history interviews with local musicians and composers, in order to demonstrate their dynamics and characteristics in a specific region.
\end{abstract}

Key words: popular music; ABC; jovem guarda; rock; oral history.

Data de recebimento do artigo: 01-08-2008

Data de aprovação do artigo: 28-08-2008 